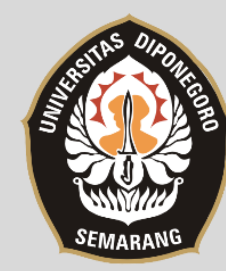

pISSN : $1829-8370$ eISSN : 2301-9069

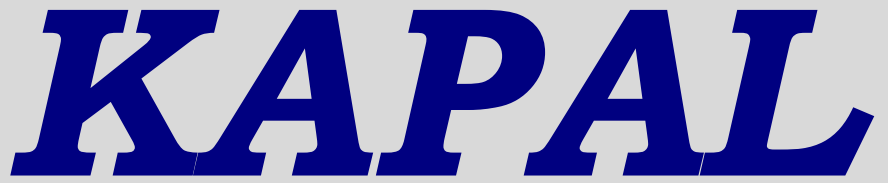

JURNAL ILMU PENGETAHUAN \& TEKNOLOGI KELAUTAN

\title{
Investigasi Dampak Insiden Tubrukan Terhadap Respon Struktur Kapal Penumpang Antar Pulau
}

\author{
Aditya Rio Prabowo ${ }^{\left.1)^{*}\right)}$, Teguh Muttaqie ${ }^{2,3)}$, Jung Min Sohn ${ }^{1,2)}$, Dong Myung Bae ${ }^{2)}$ \\ ${ }^{1)}$ Department of Marine Convergence Design, Pukyong National University \\ Nam-gu, Yongso-ro 45, Busan, Korea Selatan 48513 \\ ${ }^{2)}$ Department of Naval Architecture and Marine Systems Engineering, Pukyong National University \\ Nam-gu, Yongso-ro 45, Busan, Korea Selatan 48513 \\ ${ }^{3}$ Badan Pengkajian dan Penerapan Teknologi \\ Jalan MH. Thamrin 8, Jakarta, Indonesia 10340
}

\begin{abstract}
Abstrak
Tujuan dari penelitian ini adalah untuk menginvestigasi dampak dari tubrukan pada struktur kapal, dan mengkuantifikasi respon yang dihasilkan oleh struktur lambung ganda. Kasus yang diaplikasikan pada penelitian didesain berdasarkan insiden tubrukan antara Roll on-Roll off (Ro-Ro) Marisa Nusantara dengan Reefer Qihang di Selat Sunda pada \# Mei 2014. Analisa dari skenario tubrukan dilaksanakan menggunakan metode elemen hingga (FEM) untuk menghasilkan prediksi dari respon kapal Ro-Ro ketika mengalami tubrukan. Untuk mendapatkan konfigurasi dan setting yang akurat, hasil analisa FEM dibandingkan dengan kalkulasi rumus empiris energi tubrukan. Studi dilanjutkan dengan menganalisa respon struktur dengan memvariasikan internal dan eksternal parameter, yaitu lokasi tubrukan dan material lambung. Berdasarkan karakteristik energi pada lokasi yang telah ditentukan, beberapa target di wilayah after-end dapat disimpulkan sebagai titik kritis jika tubrukan terjadi di pada lokasi ini. Di lain pihak, dengan mentukan target pada struktur dan konstruksi yang sama, penggunaan baja karbon menengah dapat memberikan hambatan struktur yang besar kepada striking ship ketika melakukan penetrasi pada lambung struck ship.
\end{abstract}

Copyright (C) 2018, KAPAL, pISSN:1829-8370, eISSN : 2301-9069

Kata Kunci : Tubrukan kapal, Ro-Ro penumpang, Lambung ganda, Metode elemen hingga

\section{PENDAHULAN}

Sejak dimulainya sejarah industri perkapalan, fenomena tubrukan sudah menarik perhatian yang luas, baik dalam kasus kecelakaan pada moda transportasi darat maupun transportasi laut. Besarnya kemungkinan kejadian tubrukan yang dipengaruhi berbagai faktor, membuat investigasi dan riset di bidang ini terus dilakukan dalam hal aktif (navigasi) maupun pasif (kapabilitas struktur).

*) Penulis Korespondensi :

Email : aditya@pukyong.ac.kr
Pada moda transportasi laut, sejarah mencatat kecelakaan besar yang melibatkan tubrukan kapal, seperti Titanic pada saat pelayaran perdananya di tahun 1912. Karena kuantitas kerugian yang begitu besar dari kecelakaan ini, pihak-pihak terkait mengadakan investigasi dan penelitian yang ditujukan untuk mengevaluasi standar aturan dan keamanan pada saat melakukan operasional di laut.

Meskipun termasuk kejadian yang kompleks, pada dasarnya tubrukan dibagi menjadi bagian, yaitu external dynamics dan internal mechanics yang keduanya saling berkaitan. Instrumen untuk menganalisa fenomena ini pun turut dikembangkan, sebagai contoh kode numerik - 
metode elemen hingga (finite element method $F E M$ ) guna meningkatkan ketelitian dan kapabilitas dalam memprediksi berbagai kriteria struktur baik saat maupun setelah tubrukan. Dalam riset menggunakan FEM, Kitamura menyatakan bahwa konfigurasi pada analisa tubrukan akan akurat ketika dimodelkan menggunakan asumsi aktual kecelakaan, metode analitik dan elemen hingga [1]. Riset mengenai tubrukan kapal telah dilakukan oleh beberapa peneliti, seperti Haris dan Amdahl [2], Prabowo [3-7] dan Calle et al. [8]. Ketiga contoh sebelumnya menggunakan FEM dalam kalkulasi, dan validasi dengan laboraorium eksperimen. Meskipun akurasi untuk konfigurasi akan semakin baik, tapi proses riset dengan metode ini akan memakan waktu yang tidak sedikit.

Mempertimbangkan metode dalam verifikasi untuk konfigurasi tubrukan dan efektifitas lama waktu riset, penelitian ini ditujukan untuk menginvestigasi perilaku struktur kapal dalam menghadapi beban tubrukan. Skenario utama dimodelkan berdasarkan insiden tubrukan kapal menggunakan FEM. Hasil dari kalkulasi numerik akan dibandingkan lagi dengan hasil kalkulasi menggunakan metode empiris. Analisa lanjutan akan ditujukan untuk mengkuantifikasi efek dari parameter yang termasuk dalam external dynamics dan internal mechanics pada saat tubrukan.

\section{METODE}

\subsection{Insiden Kecelakaan}

Referensi untuk pemodalan kasus kecelakaan diambil berdasarkan kasus kecelakaan yang melibatkan Ro-Ro Marisa Nusantara dan Reefer Qi Hang di Selat Sunda. Pada saat tubrukan, Ro-Ro bertindak sebagai struck ship, sedangkan reefer berperan sebagai striking ship [9]. Diprediksi, dalam kecelakaan, striking ship melaju dengan kecepatan 12 kts., atau pada kisaran $6.17 \mathrm{~m} / \mathrm{s}$. Hasil survey lapangan, kerusakan pada struck ship diperoleh dengan panjang 7 meter, lebar 5 meter, dan kedalaman 2 meter. Lebih detail, sobekan pada lambung terdapat pada lambung amping diantara main deck dan middle deck.

\subsection{Prosedur Investigasi}

Metode nonlinier FEM akan digunakan untuk melakukan kalkulasi numerik berdasakan aktual skenario tubrukan, dengan target keluaran tingkat kerusakan dan energi tubrukan. Hasil dari kalkulasi energi akan dibandingkan dengan perhitungan yang menggunakan formula empiris. Pada riset ini, rumus yang dikembangkan oleh Zhang [10] akan digunakan untuk menghitung energi berdasarkan kerusakan pada lambung samping struck ship. Persamaan matematis dari rumus empiris dibagi berdasarkan dua bentuk kerusakan, yaitu lipatan dan robekan, sesuai dengan yang ditulis pada persamaan 1 dan 2 .

$$
\begin{gathered}
E=3.50\left(\frac{t}{d}\right)^{0.67} \sigma_{0} R_{T} \\
E=3.21\left(\frac{t}{l}\right)^{0.6} \sigma_{0} R_{T}
\end{gathered}
$$

dimana: $E=$ energi terserap dalam tubrukan, $t=$ tebal plat rata-rata, $d=$ tebal plat rata-rata pada penampang subjek yang rusak, $l=$ panjang kritis kerusakan, $\sigma_{0}=$ flow stress dan $R_{t}=$ volume material yang rusak.

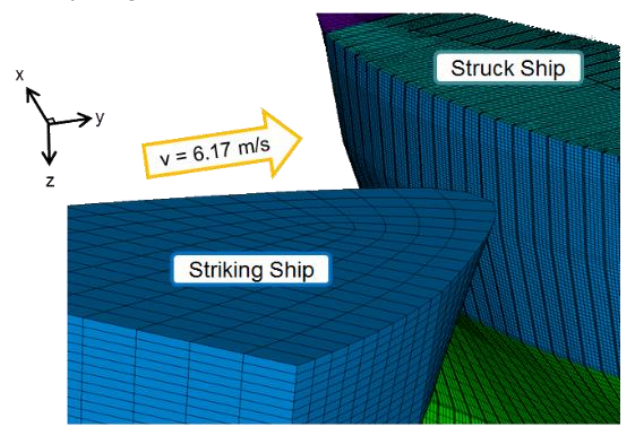

Gambar 1. Illustration of collision process.

Titik target pada struck ship ditentukan pada lambung samping diantara main deck dan middle deck. Kecepatan striking ship saat kontak dengan target ditentukan sebesar $6.17 \mathrm{~m} / \mathrm{s}$, dimana struck ship diberi batasan olah gerak aksial dan rotasional untuk pada semua arah. Kedua kapal didesain secara numerik menggunakan shell element dengan tipe formulasi Belytschko-Tsay diimplementasikan pada model [11]. Ilustrasi dari skenario tubrukan diberikan pada Gambar 1.
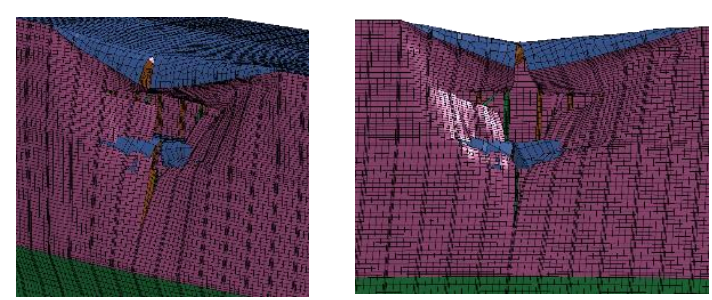

(a)

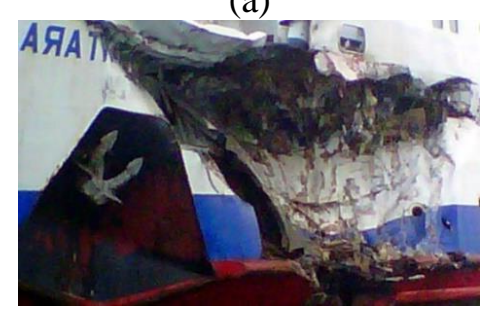

(b)

Gambar 2. Kontur kerusakan pada struck ship: (a) analisa FEM and (b) aktual insiden. 
Hasil kalkulasi mengenai bentuk kerusakan pada struck ship menggunakan metode elemen hingga dibandingkan dengan kerusakan dari aktual insiden tubrukan (Gambar 2). Dari segi geometri, kerusakan yang dihasilkan secara numerik mengindikasikan kesamaan yang baik. Kesimpulan ini juga didukung dengan tingkat kerusakan yang serupa dengan insiden tubrukan, yaitu panjang 7 meter, lebar $4.5 \mathrm{~m}$, dan kedalaman 2 meter.

Setelah verifikasi dalam hal kerusakan diselesaikan, perbandingan untuk energi tubrukan (Tabel 1) akan dilakukan pada tahap sebelumnya. Dengan kalkulasi empiris menggunakan formula dari Zhang, didapat bahwa perbedaan dengan FEM sangat kecil, yaitu dibawah 5\%.

Tabel 1. Verifikasi Energi Tubrukan.

\begin{tabular}{cccc}
\hline \multirow{2}{*}{ Kasus } & \multicolumn{2}{c}{ Energi (MJ) } & Selisih \\
& FEM & Empiris & $(\boldsymbol{\%})$ \\
\hline Tubrukan kapal & 6.91344 & 6.96731 & 0.7732 \\
\hline
\end{tabular}

\subsection{Parameter untuk Analisa Tubrukan}

Konfigurasi metode elemen hingga (FEM) di analisa sebelumnya akan digunakan untuk simulasi numerik dengan ANSYS LS-DYNA [12] tubrukan kapal dengan parameter berbeda, yaitu lokasi tubrukan dan material lambung kapal. Variasi dalam hal lokasi akan ditentukan pada arah longitudinal lambung kapal, dan tiga material berbeda seperti yang diberikan pada Tabel 2, akan diaplikasikan pada geometri kapal. Detail setting untuk simulasi diberikan sebagai berikut:

1. Jarak antara dua target ditetapkan pada dua web yang berdekatan dengan $l<2 \mathrm{~m}$.

2. Baja pada lambung kapal diasumsikan sebagai plastic-kinematic material [13].

3. Waktu simulasi dibatasi sangat pendek, yaitu $0.567 \mathrm{~s}$ untuk memenuhi kriteria beban impak.

4. Kecepatan striking ship diberikan sebesar 6.17 $\mathrm{m} / \mathrm{s}$ berdasarkan aktual insiden.

5. Koefisien gesek antara baja diaplikasikan pada konfigurasi kontak.

Tabel 2. Material Kapal pada Simulasi Numerik.

\begin{tabular}{cccc}
\hline Properties & $\begin{array}{c}\text { Low- } \\
\text { carbon }\end{array}$ & $\begin{array}{c}\text { Medium- } \\
\text { carbon }\end{array}$ & $\begin{array}{c}\text { Alloy } \\
\text { Steel }\end{array}$ \\
\hline Density $\left(\mathrm{kg} / \mathrm{m}^{3}\right)$ & 7865 & 7850 & 7850 \\
Poisson's ratio & 0.27 & 0.3 & 0.29 \\
$\begin{array}{c}\text { Yield strength } \\
\text { (MPa) }\end{array}$ & 310 & 440 & 315 \\
$\begin{array}{c}\text { Young's modulus } \\
\text { (MPa) }\end{array}$ & 200000 & 210000 & 200000 \\
\hline
\end{tabular}

\section{HASIL DAN PEMBAHASAN}

Kalkulasi energi tubrukan menggunakan metode elemen hingga akan dipresentasikan pada bagian ini. Energi diberikan berdasarkan lokasi, yaitu fore-end pada Gambar 3, dan midship pada Gambar 4. Kedua lokasi mengindikasikan bahwa perubahan lokasi target di arah longitudinal tidak menunjukkan perubahan yang signifikan. Namun, dapat dilihat bahwa perbedaan antara di fore-end relative lebih besar dibandingkan dengan di daerah midship. Pola energi seperti ini muncul disebabkan perbedaan geometri kedia lokasi. Penampang pada fore-end saat tubrukan cenderung berbeda di arah longitudinal dikarenakan membetuk streamline. Di lain pihak, midship memiliki penampang berbentuk konstan dan lurus, sehingga menghasilkan energi tubrukan yang mirip. Berdasarkan hasil, direkomendasikan pada saat penentuan konfigurasi tubrukan, jarak antara kedua target lebih besar daripada $2 \mathrm{~m}$ untuk mendapatkan perbedaan yang signifikan. Dalam hal kekuatan struktur lambung, perbandingan antara kedua lokasi menunjukan bahwa midship lebih kuat daripada fore-end dengan estimasi diatas $30 \%$ disaat menerima beban tubrukan dari arah samping.

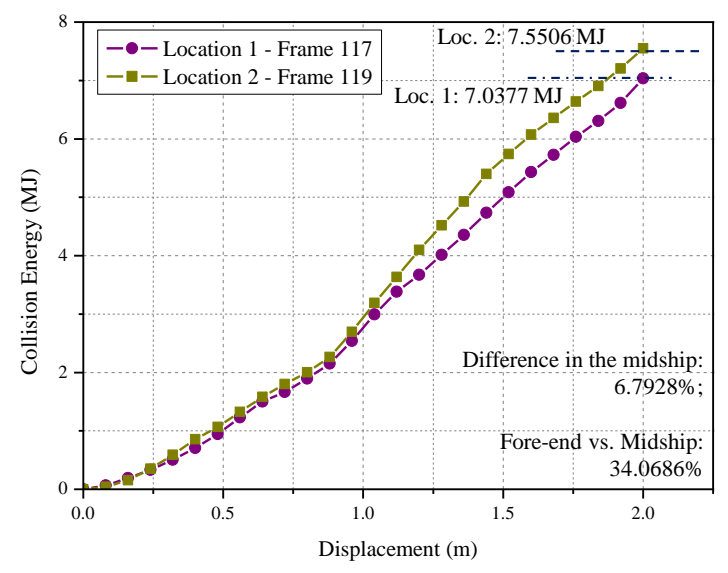

Gambar 3. Karakteristik energi tubrukan untuk lokasi fore-end.

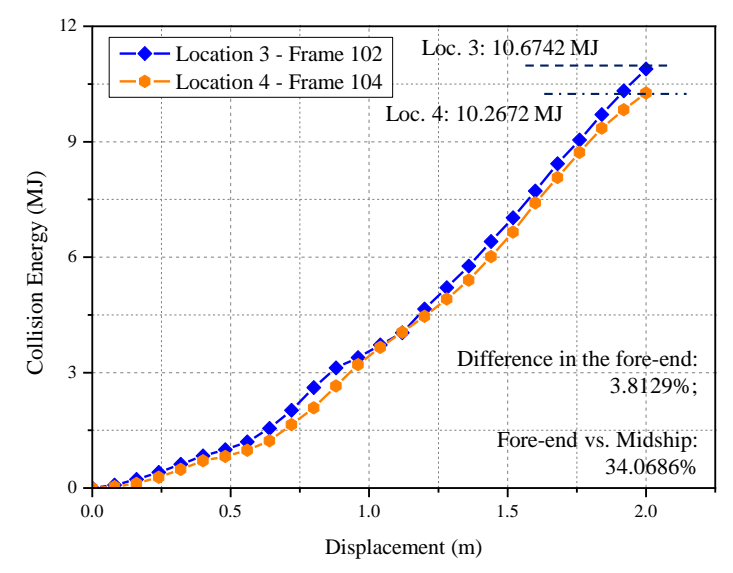

Gambar 4. Energi tubrukan untuk target lokasi midship. 

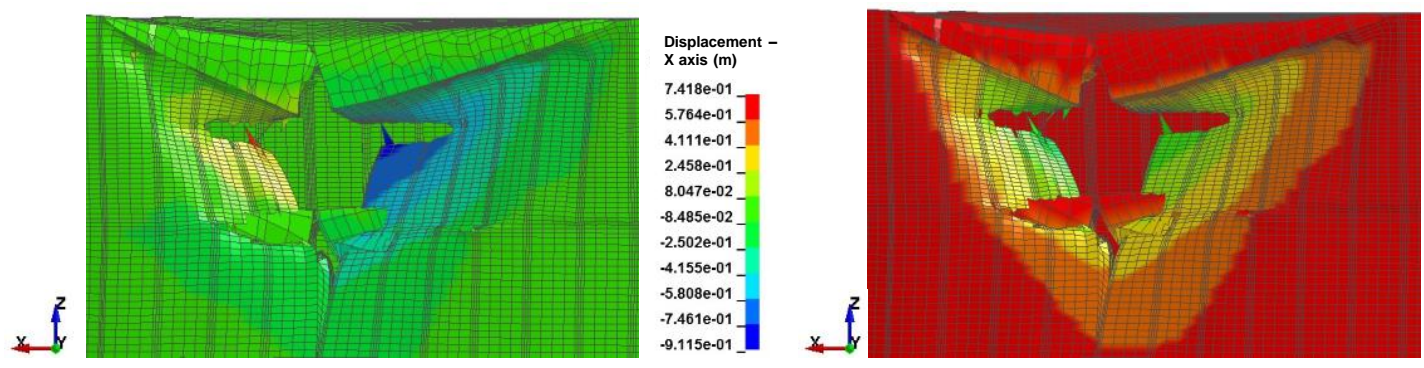

Displacement -
Y axis (m)

Yaxis $(m)$

$-3.106 \mathrm{e}-01$

$-6.648 \mathrm{e}-01$ _

$-1.019 \mathrm{e}+00$

$1.373 \mathrm{e}+00$

$.082 \mathrm{e}+00$

$2.436 \mathrm{e}+00$

$-2.790 \mathrm{e}+00$

$-3.144 \mathrm{e}+00$

$-9.115 \mathrm{e}-01$

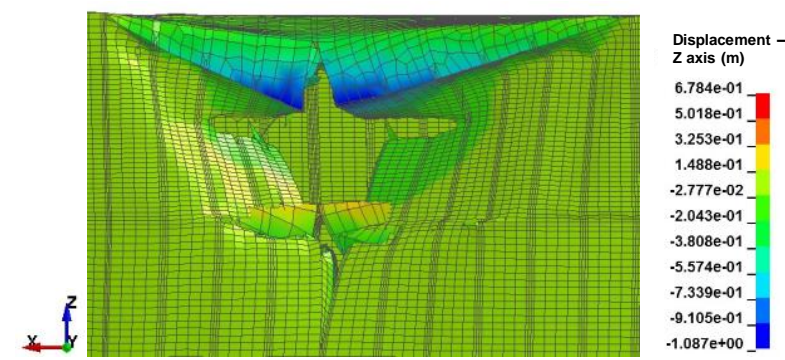

Gambar 5. Kerusakan pada lokasi no.1 di bagian struktur fore-end.
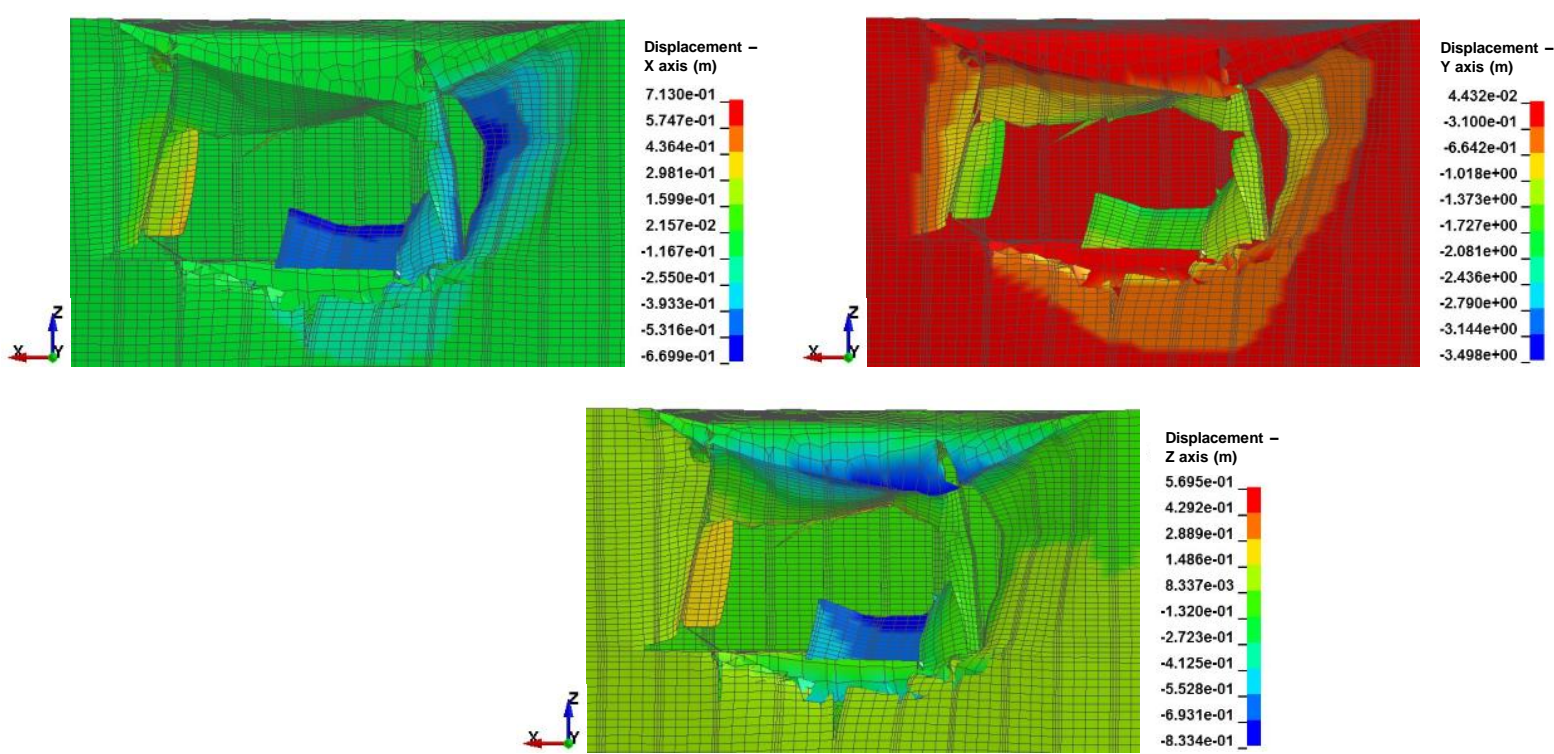

Gambar 6. Kerusakan pada lokasi no.2 di bagian struktur fore-end.

Dalam hal tingkat kerusakan setelah tubrukan, persebaran deformasi pada lambung kapal struck ship menunjukkan keparahan hingga pada main deck untuk lokasi fore-end. Seperti yang diberikan pada Gambar 5 dan 6, pada ujung main deck, kerusakan dalam bentuk robekan juga muncul, bersamaan dengan sobekan pada bagian lambung dibawah middle deck. Berlawanan dengan hasil yang ditunjukkan fore-end, kerusakan pada lambung bagian midship (Gambar 7 dan 8) tidak mencapai bagian atas (main deck) ataupun lebih rendah daripada middle deck.

Pererhatian selanjutnya ditujukan pada efek material baja di lambung kapal saat menghadapi tubrukan. Hasil pada gambar 9 menunjukkan bahwa perbedaan yang signifikan terjadi pada lowcarbon dan medium-carbon steel.
Dapat disimpulkan bahwa kenaikan nilai yield strength akan sebanding dengan kemampuan hambatan struktur dalam menghadapi tubrukan. Hal ini sesuai dengan teori material dimana baja dengan yield lebih tinggi akan lebih sulit dirusak saat kontak, yang lebih jauh pengaruh yield ini akan meningkatkan impact resistance. Akan tetapi, anomali terjadi pada low alloy yang menghasilkan energi lebih kecil daripada baja-karbon rendah, meskipun low alloy memiliki yield lebih tinggi. Temuan mengenai material baja menunjukkan bahwa pada saat perbedaan yield tidak signifikan, atau dibawah $1.587 \%$, density akan mempengaruhi hasil kalkulasi energi. Lebih jauh, dapat disimpulkan bahwa volume material yang rusak akibat tubrukan juga akan lebih kecil meskipun suatu material memiliki yield lebih tinggi. 

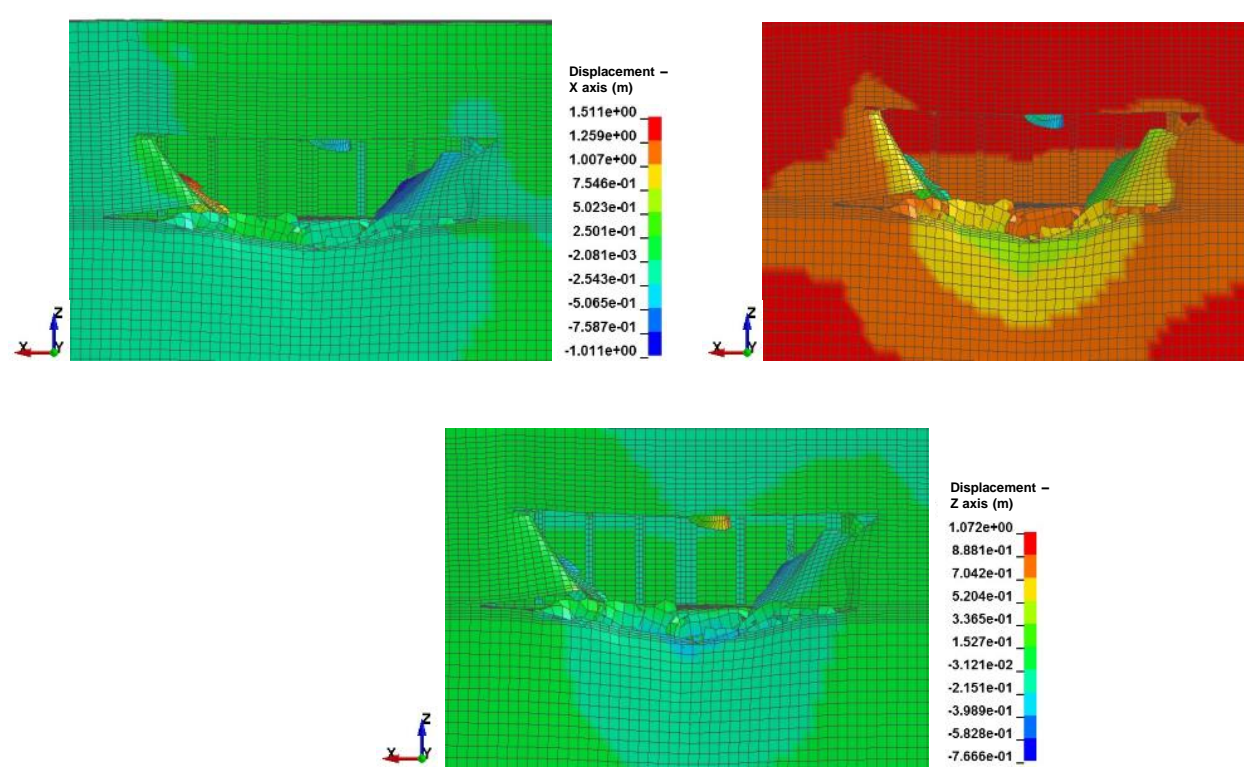

Gambar 7. Kerusakan pada lokasi no.3 di bagian struktur midship.
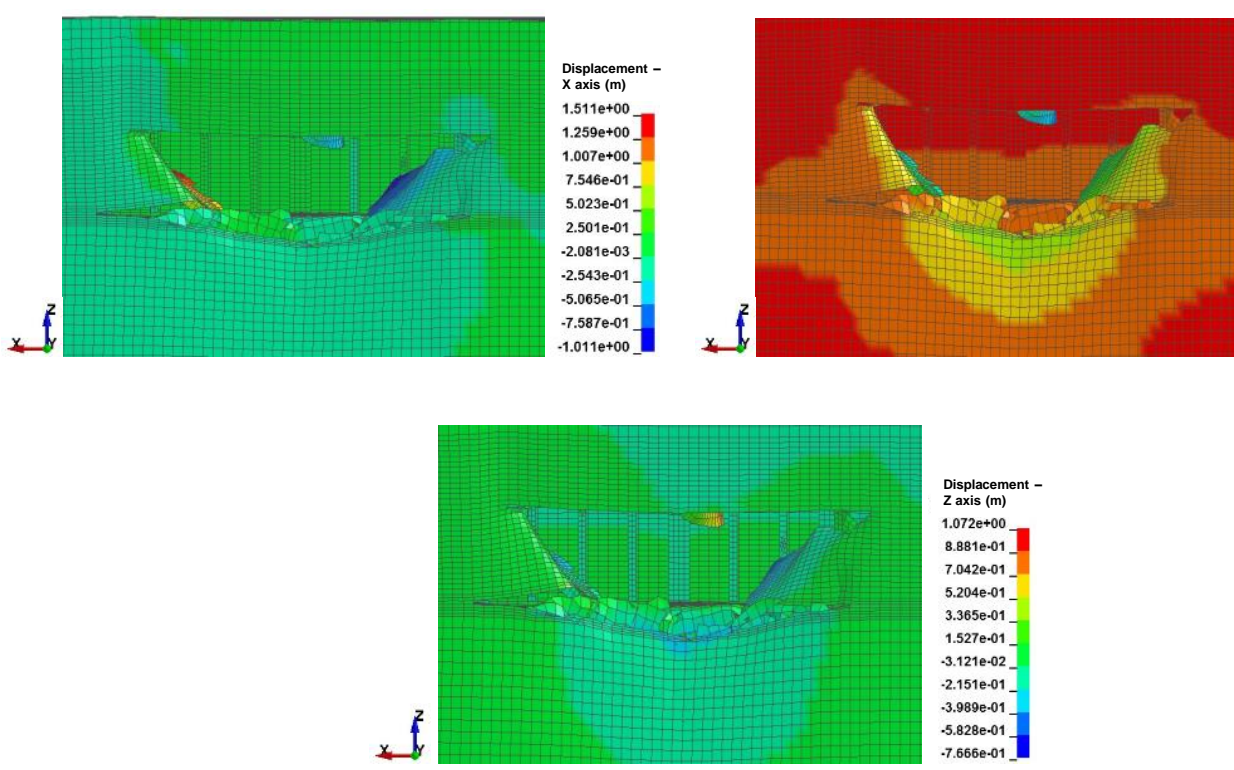

Gambar 8. Kerusakan pada lokasi no.4 di bagian struktur midship.

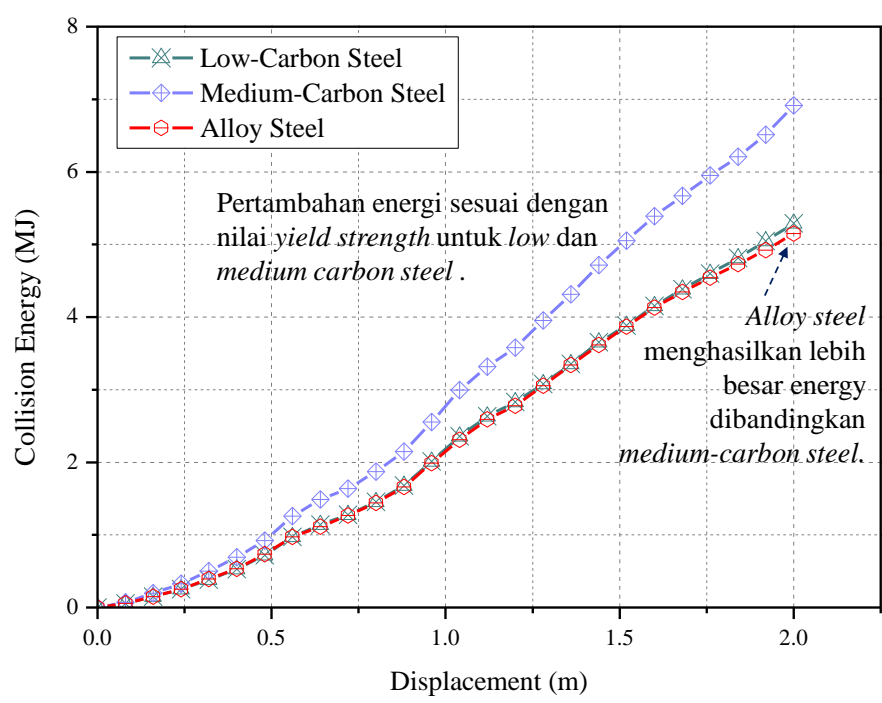

Gambar 9. Pola energi tubrukan untuk ketiga material yang digunakan pada analisa. 


\section{KESIMPULAN}

Penelitian ini menyajikan sebuah studi mengenai investigasi beberapa kasus tubrukan kapal yang didesain agar mewakili internal dan eksternal parameter pada tubrukan kapal. Metode elemen hingga digunakan sebagai media kalkulasi skenario tubrukan. Konfigurasi dari metode ini berhasil diverifikasi dengan membandingkan dengan kasus tubrukan aktual dan formula empiris. Pada analisa kasus tahap lanjut, didapat bahwa pengaruh target lokasi secara keseluruhan menunjukkan perbedaan kapabilitas yang cukup signifikan dalam menghadapi beban impak. Namun perlu diperhatikan bahwa dalam observasi pada target lokasi yang sama (contoh: fore-end atau midship), perbedaan jarak sangat mentukan perilaku energi tubrukan. Agar pengamatan pada respon struktur dapat dilakukan dengan jelas, rekomendasi diberikan dalam hal penetapan jarak antar target. Pada lokasi yang sama, jarak ini harus diatas 2 meter. Mengenai parameter baja kapal, density akan berpengaruh pada energi tubrukan ketika perbedaan pada aspek yield strength tidak signifikan. Review pada studi yang membahas mengenai dampak properti baja terhadap subjek berbasis baja sangat disarankan untuk mendapat referensi yang relevan dalam mendefinisikan material model pada analisa tubrukan.

\section{DAFTAR PUSTAKA}

[1] O. Kitamura, "FEM Approach to the Simulation of Collision and Grounding Damage," Marine Structures, vol. 15, pp. 403428, 2002.

[2] S. Haris, J. Amdahl, "Analyis of Ship-Ship Collision Damage Accounting For Bow and Side Deformation Interaction," Marine Structures, vol. 32, pp. 18-48, 2013.

[3] A.R. Prabowo, D.M. Bae, J.M. Sohn, A.F. Zakki, B. Cao, J.H. Cho, "Effects of the Rebounding of a Striking Ship on Structural Crashworthiness during Ship-Ship Collision," Thin-Walled Structures, vol. 115, pp. 225239, 2017.

[4] A.R. Prabowo, D.M. Bae, J.H. Cho, J.M. Sohn, "Analysis of Structural Crashworthiness and Estimating Safety Limit Accounting for Ship Collisions on Strait Territory," Latin American Journal of Solids and Structures, vol. 14, pp. 1594-1613, 2017.
[5] D.M. Bae, A.R. Prabowo, B. Cao, J.M. Sohn, A.F. Zakki, Q. Wang, "Numerical Simulation for the Collision Between Side Structure and Level Ice in Event of Side Impact Scenario," Latin American Journal of Solids and Structures, vol. 13, pp. 2991-3004, 2016.

[6] A.R. Prabowo, B. Cao, D.M. Bae, S.Y. Bae, A.F. Zakki, J.M. Sohn, "Structural Analysis of the Double Bottom Structure During Ship Grounding by Finite Element Approach," Latin American Journal of Solids and Structures, vol. 14, pp. 1-18, 2017.

[7] A.R. Prabowo, S.J. Baek, H.J. Cho, J.H. Byeon, D.M. Bae, J.M. Sohn, "The Effectiveness of Thin-Walled Hull Structures Against Collision Impact," Latin American Journal of Solids and Structures, vol. 14, pp. 1345-1360, 2017.

[8] M.A.G. Calle, R.E. Oshiro, M. Alves, "Ship Collision and Grounding: Scaled Experiments and Numerical Analysis," International Journal of Impact Engineering, vol. 103, pp. 195-210, 2017.

[9] A.R. Prabowo, D.M. Bae, J.M. Sohn, J.H. Cho, "Performance Assessment on a Variety of Double Side Structure During Collision Interaction with Other Ship," Curved and Layered Structures, vol. 4, pp. 255-271, 2017.

[10] S. Zhang, P.T. Pedersen, "A Method for Ship Collision Damage and Energy Absorption Analysis and Its Validation," Ships and Offshore Structures, vol. 12, pp. S11-S20, 2016.

[11] D.M. Bae, A.R. Prabowo, B. Cao, A.F. Zakki, G.D. Haryadi, " Study on Collision Between Two Ships Using Selected Parameters in Collision Simulation," Journal of Marine Science and Application, vol. 15, pp. 63-72, 2016.

[12] ANSYS, ANSYS LS-DYNA User's Guide, Pensylvania: ANSYS, Inc., 2017.

[13] A.R. Prabowo, D.M. Bae, J.M. Sohn, B. Cao, "Energy behavior on side structure in event of ship collision subjected to external parameters," Heliyon, vol. 2, e00192, 2016. 